\title{
ANALISIS STATIK BEBAN GEMPA PADA PERENCANAAN STRUKTUR GEDUNG REKTORAT UNHASY TEBUIRENG JOMBANG
}

\author{
Titin Sundari ${ }^{1 *}$, Abdiyah Amudi, Totok Yulianto, Rahma Ramadhani \\ ${ }^{1}$ Dosen Teknik Sipil Fakultas Teknik Universitas Hasyim Asy’Ari Tebuireng \\ Jombang \\ *Korespondensi: tari1273@yahoo.co.id
}

\begin{abstract}
Static analysis is a simplification of dynamic analysis. Earthquake vibrations cause lateral forces at the base of the structure, and will be distributed on each floor of the building as lateral level forces. This analysis is suitable for regular building shapes. In accordance with SNI 1726: 2012, the value of the base shear force V is 103,039 $\mathrm{kg}$ for the $X$ and $Y$ directions. The displacement value is $54 \mathrm{~mm}$ and drift ratio $\Delta<\Delta a$ (allowable)
\end{abstract}

KeywordS : Analysis, base, displacement, drift, static, SNI 1726:2012

\section{PENDAHULUAN}

Wilayah Indonesia sebagian besar daerahnya rawan gempa, untuk itu perencanaan gedung tahan gempa sangatlah penting. Hal ini telah diatur dalam standar gempa terbaru yaitu SNI 1726: 2012 tentang "Tata Cara Perencanaan Ketahanan Gempa untuk Struktur Bangunan Gedung dan Non Gedung" yang menggantikan standar sebelumnya yaitu SNI 03-1726-2002. Dalam perhitungan gaya gempa rencana ini bisa dihitung dengan analisis statik ekivalen.

Analisis statik hanya untuk bangunan yang bentuknya berarutan dan yang diperhitungkan massa bangunan saja. Untuk analisis perhitungan beban gempa ini digunakan software SAP 2000 versi 14[1]. Hasil dari analisis ini didapatkan nilai gaya geser dasar (base shear), displacement, dan simpangan antar lantai harus lebih kecil dari yang diijinkan.

\section{TINJAUAN PUSTAKA}

$\begin{array}{cccr}\text { Analisis } & \text { beban } & \text { statik } & \text { ekivalen } \\ \text { merupakan } & \text { analisis } & \text { struktur } & \text { yang }\end{array}$
mengasumsikan bahwa beban statik horizontal diperoleh dari pengaruh respon ragam getar gempa pertama. Analisis statik ini cocok untuk bangunan yang berbentuk beraturan, perhitungan beban gempa nominal dapat diasumsikan sebagai beban gempa statik ekivalen yang bekerja pada pusat massa lantai-lantai tingkat [2][3].

Berdasarkan SNI 03-1726-2002[4], persyaratan bangunan gedung beraturan sebagai berikut:

(a) Tinggi maksimum $40 \mathrm{~m}$ atau 10 tingkat.

(b) Denah gedung persegi panjang, tidak ada tonjolan dan jika ada harus $\leq 25 \%$ dari ukuran denah struktur gedung.

(c) Denah struktur tidak ada coakan sudut dan jika ada, harus $\leq 15 \%$

(d)Dalam arah vertikal tidak ada loncatan bidang muka sehingga luas menjulang < $75 \%$ luas bagian bawahnya.

(e) Sistem struktur, tanpa adanya tingkat lunak yaitu tingkat dengan kekakuan lateral $<75 \%$ tingkat diatasnya.

(f) Berat tiap lantai hampir sama, tidak ada berat yang $>150 \%$ berat rata-rata.

(g) Sistem struktur melalui sumbu-sumbu yang sejajar dan orthogonal.

(h) Unsur vertikal penahan beban dan titik berat massa bangunan menerus ke bawah

(i) Lubang pada lantai tingkat tidak melebihi $50 \%$ luas lantai.

Prosedur analisis beban gempa sesuai SNI 1726: 2012[2] untuk bangunan gedung adalah sebagai berikut, yaitu menentukan:

(a) Faktor keutamaan gempa (Ie) dan kategori 
resiko struktur (I-IV)

(b) Parameter gempa $\left(S s, S_{I}\right)$

(c) Kelas situs $(S A-S F)$

(d) Koefisien situs dan paramater respons spektral gempa maksimum risiko-tertarget $\left(\mathrm{MCE}_{\mathrm{R}}\right)$

(e) Spektrum respons desain

(f) Kategori desain seismic/KDS $(A-D)$

(g) Sistem struktur dan parameternya $\left(R, C_{d}\right.$, $\left.\Omega_{o}\right)$

(h) Batasan Perioda Fundamental Struktur (T)

(i) Geser Dasar Seismik

Sesuai SNI 1726:2012 pasal 7.8, gaya geser dasar seismic, $V$, dihitung dengan:

$V=C_{s^{*}} W$

$C_{s}=$ koefisien respon seismic

$W=$ berat seismik efektif

$C_{s}=\frac{S_{D S}}{\left(\frac{R}{V_{e}}\right)}$

$S_{D S}=$ parameter percepatan respons disain perioda pendek

$R=$ faktor modifikasi respon

$I e=$ faktor keutamaan gempa

$C_{s}$ pada rumus (2) tidak boleh lebih dari

$C_{s}=\frac{S_{D_{1}}}{T\left(\frac{R}{I_{e}}\right)}$

dan tidak lebih kecil dari

$C_{s}=0,044 . S_{D S^{\prime}} \mathrm{Ie} \geq 0,01$

Untuk struktur di lokasi $S_{1} \geq 0,6 \mathrm{~g}$ maka $C_{s}$ tidak lebih kecil dari

Cs $=\frac{0,5 S 1}{\left(\frac{R}{V_{e}}\right)}$

Dengan:

$S_{D I}=$ parameter percepatan respons disain perioda 1 detik.

$T=$ periode fundamental struktur (detik).

$S_{I}=$ parameter percepatan respon maksimum yang dipetakan.

Gaya lateral $(F x)$ yang timbul di semua tingkat harus ditentukan dengan rumus:

$$
F x=\frac{W x h x^{k}}{\Sigma_{i=1}^{n} W i h i^{k}} V
$$

Dengan,

$V$ = gaya gempa disain

$W i(W x)=$ berat total seismik efektif pada tingkat $i$ atau tingkat $x$

$h i(h x)=$ tinggi tingkat $i$ atau tingkat $x \quad(\mathrm{~m})$

$k=$ eksponen yang berhubungan dengan $\mathrm{T}$

struktur, yang besarnya:

$k=1$, dengan perioda $\leq 0,5$ detik.

$k=2$, dengan perioda $\geq 2,5$ detik. $k=$ interpolasi linier antara 1 dan 2 dengan periode 0,5 detik sampai dengan 2,5 detik. Simpangan antar lantai, sesuai SNI 1726:2012 seperti Gambar 1.

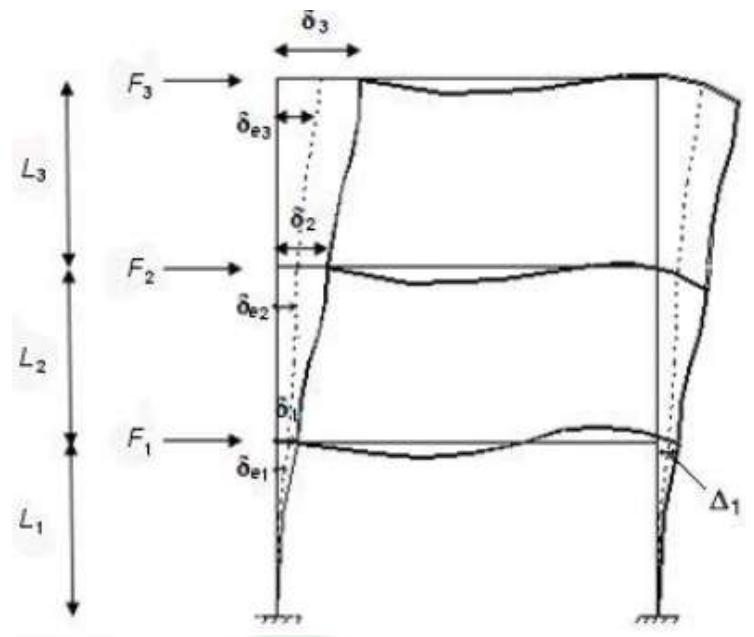

Tingkat 3

$F_{3}$ = gaya gempa desain tingkat kekuatan

$\delta_{e 3}=$ perpindahan elastis yang dihitung akibat gaya gempa desain tingkat kekuatan

$\delta_{3}=C_{d} \delta_{6} / I_{E}=$ perpindahan yang diperbesar

$\Delta_{3}=\left(\delta_{b_{3}}-\delta_{e^{2}}\right) C_{d} / I_{E} \leq \Delta_{a}($ Tabel 16)

\section{Tingkat 2}

$F_{2}=$ gaya gempa desain tingkat kekuatan

$\delta_{02}=$ perpindahan elastis yang dihitung akibat gaya gempa desain tingkat kekuatan

$\delta_{2}=C_{d} \delta_{2} / I_{E}=$ perpindahan yang diperbesar

$\Delta_{2}=\left(\delta_{e 2}-\delta_{e 1}\right) C_{d} I_{E} \leq \Delta_{a}$ (Tabel 16)

\section{Tingkat 1}

$F_{1}$ = gaya gempa desain tingkat kekuatan

$\delta_{21}=$ perpindahan elastis yang dihitung akibat gaya gempa desain tingkat kekuatan

$\delta_{1}=C_{d} \delta_{e_{1}} / I_{E}=$ perpindahan yang diperbesar

$\Delta_{1}=\delta_{1} \leq \Delta_{a} \quad$ (Tabel 16)

$\Delta_{1} \quad$ = Simpangan antar lantai

$\Delta_{i} / L_{\mathrm{i}}=$ Rasio simpangan antar lantai

$\delta_{3}=$ Perpindahan total

Gambar 1. Simpangan Antar Lantai [2]

\section{METODE PENELITIAN}

Penelitian dilaksanakan di kampus Universitas Hasyim Asy 'Ari dengan obyek penelitian beban gempa statik ekivalen pada perencanaan struktur Gedung Rektorat Unhasy Tebuireng Jombang. 


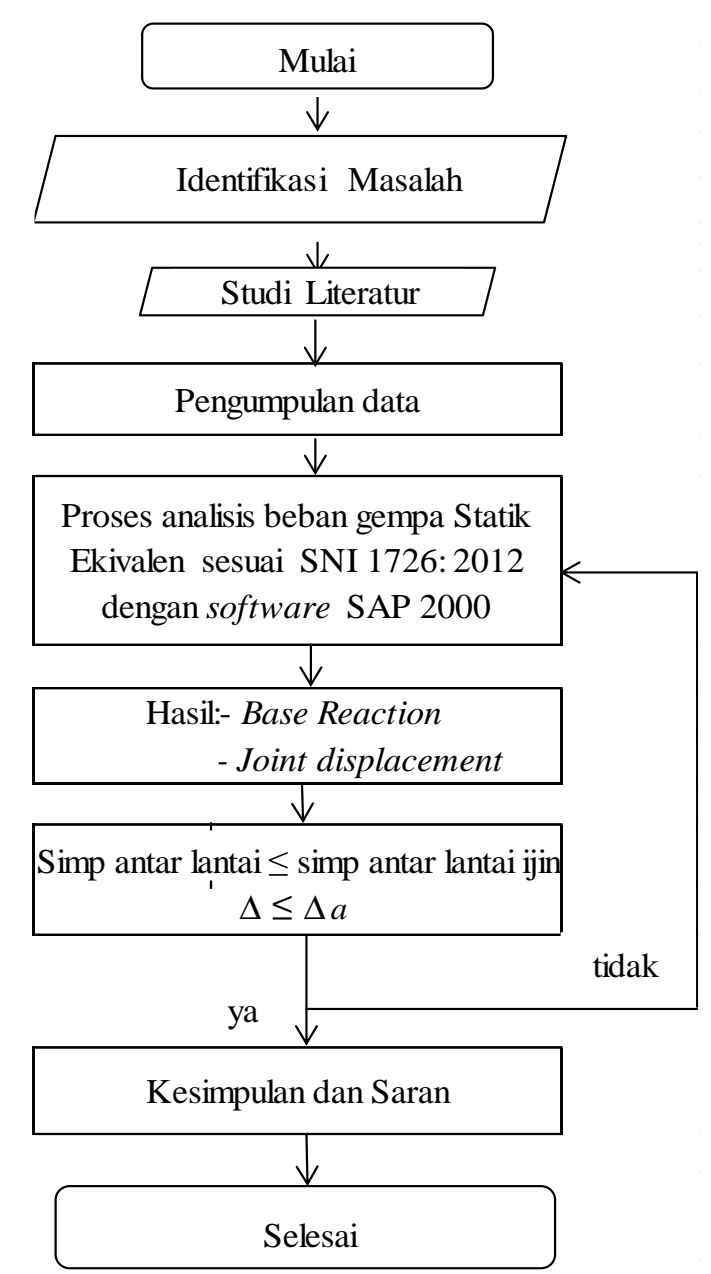

Gambar 2. Diagram Alir Penelitian

\section{HASIL DAN PEMBAHASAN}

4.1 Data Perencanaan

(a) Gambar rencana bangunan lantai sampai dengan lantai 8

(b) Mutu bahan $f^{\prime} c=30 \mathrm{MPa}$ $f y=240 \mathrm{MPa}$ dan $400 \mathrm{MPa}$

(c) Penampang balok $350 \times 600 \mathrm{~mm} 2$ kolom 700x700 mm2 pelat lantai tebal $130 \mathrm{~mm}$ pelat atap tebal $100 \mathrm{~mm}$

(d) Data tanah, titik sondir:

(S-1), lapisan tanah keras $9,4 \mathrm{~m}$. (S-2), lapisan tanah keras 14,0 m. (S-3), lapisan tanah keras $\quad 9,2 \mathrm{~m}$.

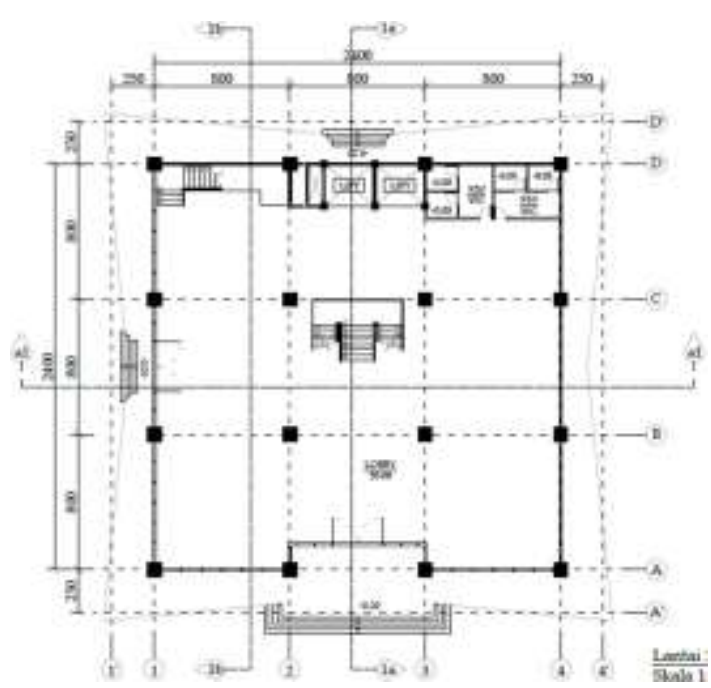

Gambar 3. Rencana Lantai 1

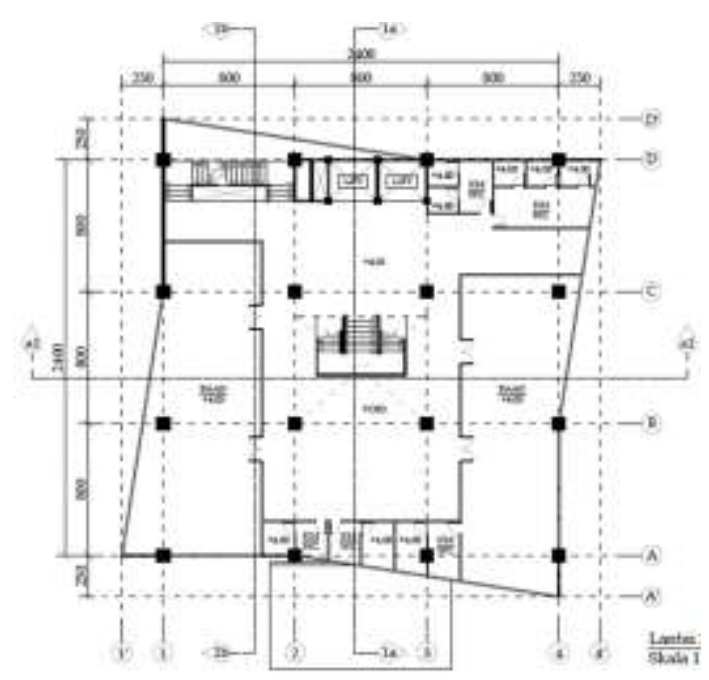

Gambar 4. Rencana Lanti 2

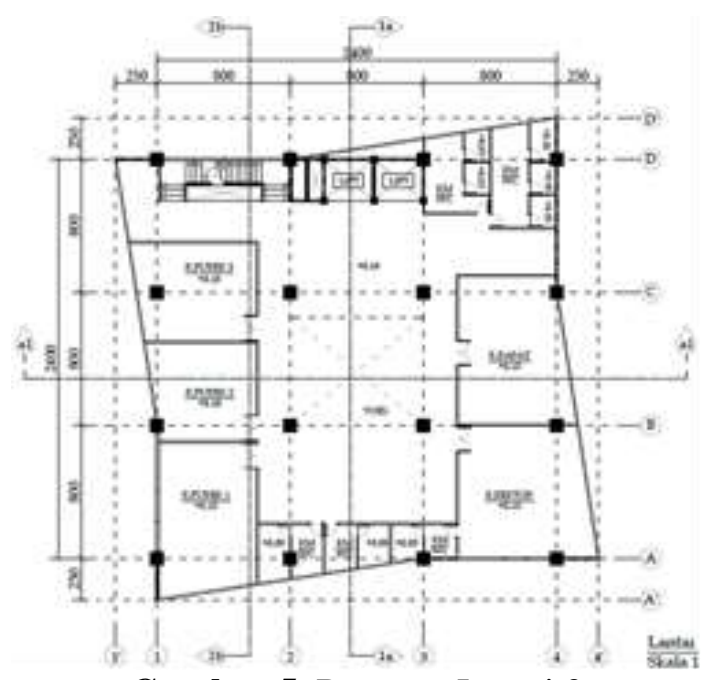

Gambar 5. Rencana Lantai 3 


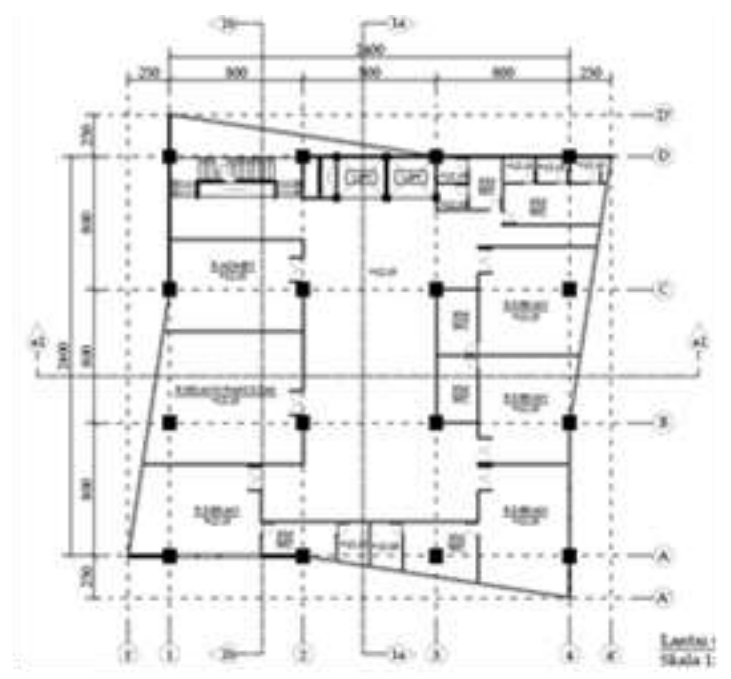

Gambar 6. Rencana Lantai 4

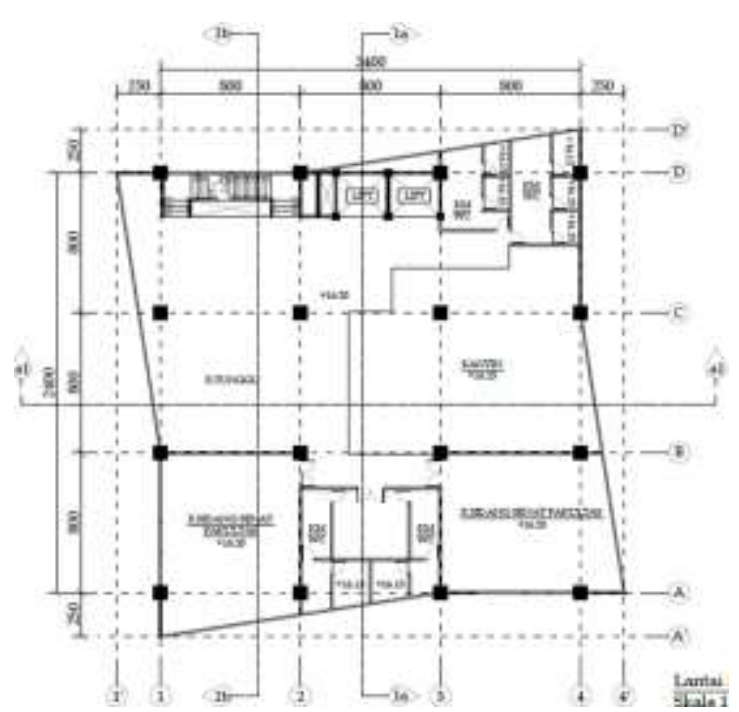

Gambar 7. Rencana Lantai 5

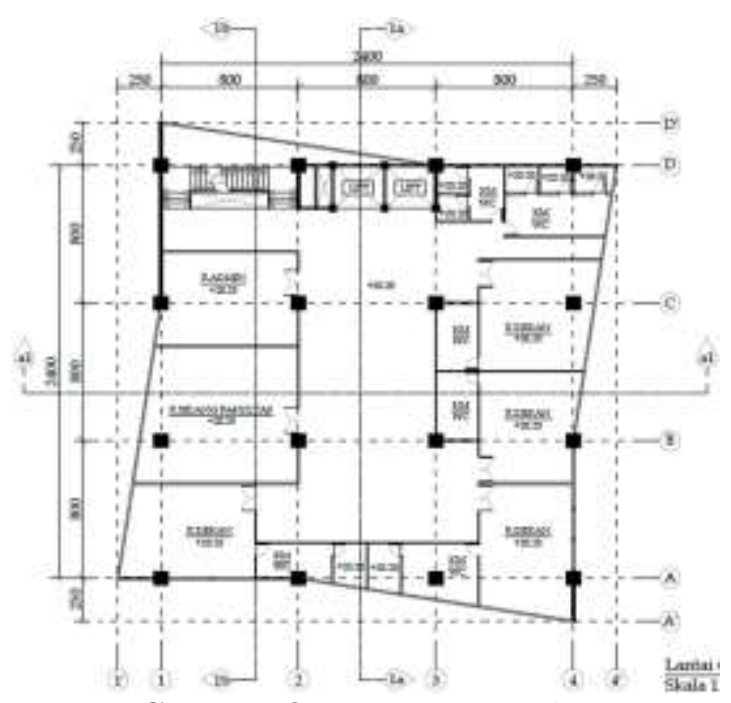

Gambar 8. Rencana Lantai 6

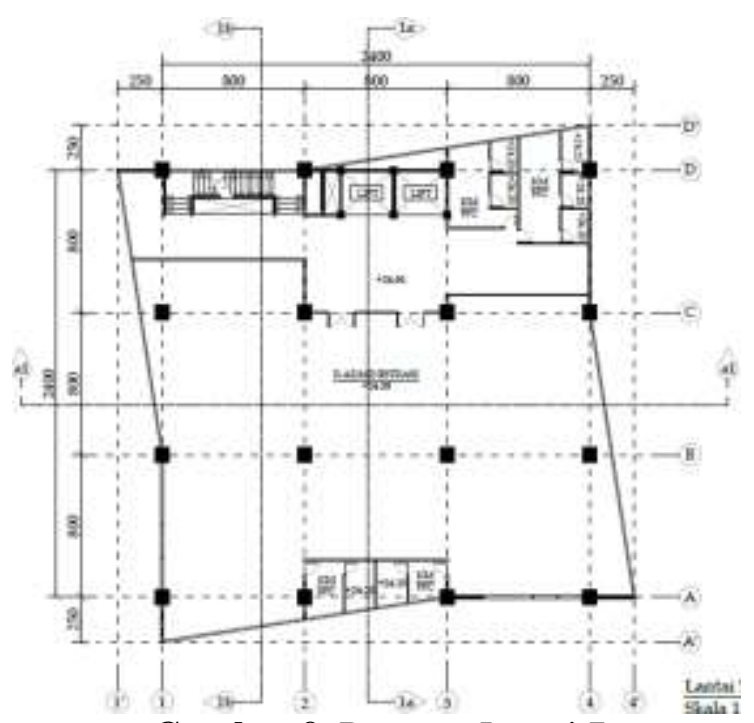

Gambar 9. Rencana Lantai 7

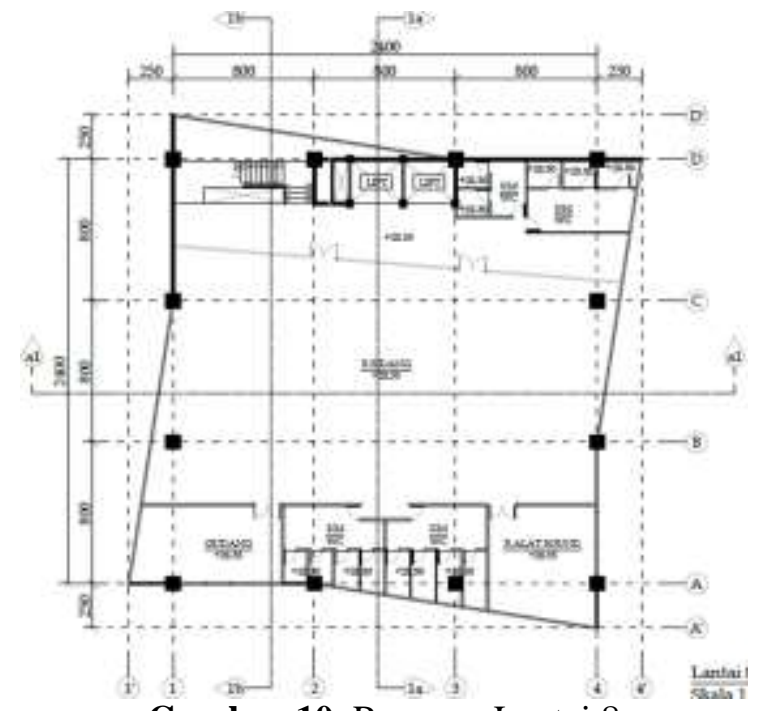

Gambar 10. Rencana Lantai 8

4.2 Analisis Beban Gempa SNI 1726: 2012

(a) Kategori resiko II, $I e=1$

(b) Parameter gempa $S_{S}$ dan $S_{1}$ [5]

(c) Kelas situs $=S C$ (batuan lunak, sangat padat, tanah keras)

(d) Koefisien - koefisien dan parameterparameter MCER (Tabel 1 dan 2)

(e) Kategori desain seismik $=D$

(f) Sistem struktur $=S R P M K$ dengan parameter sistem faktor $R=8 ; \Omega_{0}=3 ; C d=5,5$

(g) Perioda fundamental struktur ( $T$ ) yang digunakan:

$$
\begin{aligned}
& T a=C_{t} \cdot h_{n}^{x} \\
& \quad=0,0466 \times 32,4^{0,9}=1,0663 \text { detik } \\
& T c=2,69369 \text { detik } \\
& C u=1,4
\end{aligned}
$$


Cu.Ta $=1,493$ detik

Jika $T c>C u . T a$ dipakai $T=C u T a$

$$
T a<T c<C u T a \text { dipakai } T=T c
$$

$$
T c<T a \quad \text { dipakai } T=T a
$$

$T c>C u$. Ta dipakai $T=1,493$ detik detik untuk arah $x$ dan $\mathrm{y}$.

Tabel 1. Nilai Parameter Gempa

\begin{tabular}{|l|c|}
\hline \multicolumn{1}{|c|}{ Parameter } & Nilai \\
\hline PGA (g) & 0.368 \\
$\mathrm{~S}_{\mathrm{S}}(\mathrm{g})$ & 0.734 \\
$\mathrm{~S}_{1}(\mathrm{~g})$ & 0.303 \\
$\mathrm{C}_{\mathrm{RS}}$ & 1.004 \\
$\mathrm{C}_{\mathrm{R} 1}$ & 0.944 \\
$\mathrm{~F}_{\mathrm{PGA}}$ & 1.032 \\
$\mathrm{~F}_{\mathrm{A}}$ & 1.106 \\
$\mathrm{~F}_{\mathrm{V}}$ & 1.497 \\
$\mathrm{PSA}$ (g) & 0.38 \\
$\mathrm{~S}_{\mathrm{MSS}}$ (g) & 0.812 \\
$\mathrm{~S}_{\mathrm{MI}}$ (g) & 0.454 \\
$\mathrm{~S}_{\mathrm{DS}}$ (g) & 0.541 \\
$\mathrm{~S}_{\mathrm{D} 1}$ (g) & 0.302 \\
$\mathrm{~T}_{0}$ (detik) & 0.112 \\
$\mathrm{~T}_{\mathrm{S}}$ (detik) & 0.558 \\
\hline
\end{tabular}

\begin{tabular}{|c|c|c|c|}
\hline T (detii2) & $\sin (x)$ & I (detik) & $21(x)$ \\
\hline$=$ & - & Ts +1.6 & 0.134 \\
\hline 0 & 0.216 & $T_{s}+1.7$ & 0.128 \\
\hline To & 0.541 & $\mathrm{Ts}+1.8$ & 0.123 \\
\hline Ts & 0.541 & $T s+1.9$ & 0.118 \\
\hline Ts $=0$ & 0.459 & $\mathrm{Ts}_{\mathrm{s}}+2$ & 0.114 \\
\hline Ist0.1 & 0.399 & $T s+2.1$ & 0.11 \\
\hline Ts+0.2 & 0.352 & $\mathrm{~T}_{\mathrm{s}+2.2}$ & 0.106 \\
\hline$T_{s}+0.3$ & 0.316 & $\mathrm{Ts}_{\mathrm{s}+2.3}$ & 0.102 \\
\hline Ts +0.4 & 0.286 & $\mathrm{Ts}+2.4$ & 0.099 \\
\hline Tst0.5 & 0.261 & $T_{s+2.5}$ & 0.096 \\
\hline Tst0.6 & 0.24 & $T_{s+2.6}$ & 0.093 \\
\hline Tst0.7 & 0.223 & $\mathrm{~T}_{s+2.7}$ & 0.09 \\
\hline Tsto. 8 & 0.207 & $T s+2.8$ & 0.087 \\
\hline Ts $=0,9$ & 0.194 & $T_{s}+2.9$ & 0.085 \\
\hline$T_{s+1}$ & 0.182 & $\mathrm{~T}_{5}+3$ & 0.083 \\
\hline Tst1.1 & 0.172 & $T s+3.1$ & 0.08 \\
\hline$T_{s+1.2}$ & 0.163 & $\mathrm{~T} s+3.2$ & 0.078 \\
\hline$T_{s+1.3}$ & 0.154 & $\mathrm{~T}_{s+3.3}$ & 0.076 \\
\hline$T_{s+1.4}$ & 0.147 & 4 & 0.076 \\
\hline Ist1.5 & 0.14 & - & - \\
\hline
\end{tabular}

Tabel 2. Nilai Spektral Respon Percepatan

(h) Gaya geser dasar seismik ( $V$ ) dan gaya lateral tingkat $(\mathrm{Fi})$ ditinjau dengan beban statik ekivalen sesuai SNI 1726: 2012dengan bantuan SAP 2000 V.14.

\subsection{Gaya Geser Statik Ekivalen}

(a) Pemodelan Struktur

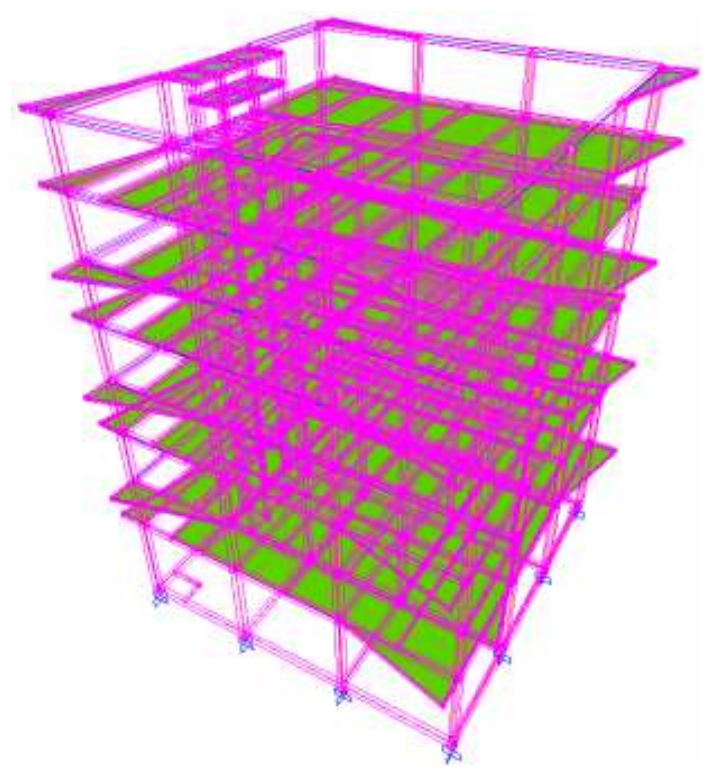

Gambar 11. Pemodelan Struktur

(b) Mendefinisikan respon spectrum gempa rencana

(c) Berat seismic struktur, dari hasil SAP 2000 diperoleh brat sendiri struktur kemudian ditambahkan berat mati dan bebban hidup sehingga diperoleh berat seismik struktur, $W$ $=4.072 .678 \mathrm{~kg}$ seperti ditabelkan pada Tabel 3.

\begin{tabular}{|c|c|c|c|c|}
\hline Landi & $\begin{array}{c}B \text { mab } \\
\text { ambahan } \\
\text { (k) }\end{array}$ & $\begin{array}{c}\text { B. Fitp } \\
\text { nobahan } \\
\text { (Ft) }\end{array}$ & $\begin{array}{c}\text { Berat senóni } \\
\text { (kg) }\end{array}$ & $\begin{array}{c}\text { Bebantal } \\
\text { (1/) }\end{array}$ \\
\hline LANTAIDASAR. & 0 & 0 & 18207 & 155207 \\
\hline L.ANAII $(+400)$ & 82300 & 55,40 & 288,157 & 420,917 \\
\hline LANTAI $(-810)$ & 82300 & 53,45 & 28241 & 420,001 \\
\hline L.MIA13 (-12.15) & 90,52 & 60,984 & 28,941 & 43447 \\
\hline L.NAIH $(-1620)$ & 90,502 & 60,884 & 28,941 & 43447 \\
\hline$-.1 N A I J(-203)$ & 90,52 & 60,984 & 282,41 & 43447 \\
\hline L.ANAI $6(-2430)$ & 90,582 & 60,854 & 28941 & 434,77 \\
\hline L.ANAIT $(-23.3)$ & 90,52 & 60384 & 289,572 & 435,01 \\
\hline ATAP LIFI $(+20.55)$ & 713 & 375 & 3880 & $9,90 !$ \\
\hline ATHP (EDUXG $(+22.40)$ & 3,618 & $19 \%$ & 6695 & 2,43 \\
\hline & & & 79,459 & 730.49 \\
\hline \multicolumn{4}{|r|}{ Behan toal $17=$} & 407268 \\
\hline
\end{tabular}

Tabel 3. Berat Seismik Struktur $(W)$

(d) Menghitung nilai gaya geser dasar seismic,

$$
\begin{aligned}
V=C_{S^{*}}, W & \\
C s \quad & =\frac{S D s}{\left(\frac{R}{l e}\right)}=\frac{0,541}{\left(\frac{8}{1}\right)} \\
& =0,067625
\end{aligned}
$$




$$
\begin{aligned}
C_{s \text { maks }} & =\frac{S_{D 1}}{T\left(\frac{R}{I e}\right)}=\frac{0,302}{1,493\left(\frac{8}{1}\right)} \\
& =0,025285 \\
C_{\text {smin }} & =0,044 . S_{D S^{\prime}} \text {. } \\
& =0,044.0,541.1 \\
= & 0,0238 \geq 0,01
\end{aligned}
$$

Maka dipakai nilai $C s=0,0253$ sehingga diperoleh nilai, $\quad V=0,0253 \times 4.072 .678$

$$
=103.039 \mathrm{~kg}
$$

\begin{tabular}{|c|c|c|c|c|c|}
\hline Tndat Latiai & $\begin{array}{c}\text { Beters Total } \\
\text { (ta) }\end{array}$ & $\begin{array}{l}2 \\
\text { (iti) }\end{array}$ & $2^{k}$ & $W, \varepsilon^{d}$ & $\begin{array}{c}F\left(-\frac{w^{2}}{\left.\partial x_{x^{2}}\right)} V\right. \\
(\mathrm{kg})\end{array}$ \\
\hline LANTAIDASAR. & 18537 & & & & \\
\hline LANTAII $(+405)$ & A291? & 405 & $\mid 6 \rightarrow x)$ & 6,904085 & 607 \\
\hline LANIAI $2(+8.10)$ & $\Delta 03,701$ & 810 & 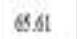 & noverso & 2623 \\
\hline LANIA1 $3(+12.15)$ & 434,477 & 12.15 & 1476 & $64,118,528$ & 6,106 \\
\hline LANTAI $4++1620)$ & $43, \pi m$ & 6.30 & $2 x+4$ & IHAR6404Q & 1084 \\
\hline LANTAI $5(+203)$ & 4,47 & 3.2 & 41006 & {$[3,162577$} & 15960 \\
\hline LANTAI $6(+2639)$ & 4,47 & 3430 & 90.2 & $256 \pm 4111$ & 24,42 \\
\hline LANTA17(+28.35) & 435,108 & 23.35 & 803.72 & $30,76+11$ & 3329 \\
\hline ATAP UTT $(-90.55)$ & 9908 & 30.55 & 93330 & 9236656 & $\mathscr{1 0}$ \\
\hline \multirow[t]{2}{*}{ ATAP CEDUNG $(+32+39)$} & 72,473 & 32.4 & Das: & 6.978899 & 724 \\
\hline & 790,469 & & & & \\
\hline$\Sigma(\pi)=$ & $4,072,678$ & & 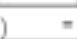 & $1,082,477504$ & \\
\hline
\end{tabular}

(e)Menghitung gaya lateral gempa

Nilai gaya lateral tingkat statik ekivalen $(F i)$ seperti pada Tabel 4 dengan nilai $\mathrm{k}=2$.

Tabel 4. Gaya Lateral Gempa Tiap Tingkat

(e) Input beban lateral gempa arah X dan $\mathrm{Y}$

Pada kasus beban EQX, diberikan beban

\begin{tabular}{|c|c|c|}
\hline \multirow{2}{*}{ Tnges Lanti } & \multicolumn{2}{|c|}{ 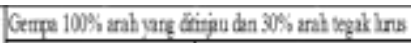 } \\
\hline & Fi $(\mathrm{g})$ & 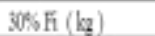 \\
\hline LANTAIDASAR & & \\
\hline LANTAI 1 (+4.05) & 65 & 197 \\
\hline LANTAI $2(+8.16)$ & 2,628 & 788 \\
\hline LANTA13 $(+12.15)$ & 6.306 & 4832 \\
\hline LANTAI4 (+1639) & 10,554 & 3,85 \\
\hline LANTAI5 (+30.25) & 16,960 & $\$ 088$ \\
\hline LANTAL $6(+24.38)$ & 24,422 & 7,307 \\
\hline LANTAI $f(+28.39)$ & 33,200 & 90.87 \\
\hline ATAPLIFT (-3055) & 20 & 364 \\
\hline ATAPCEDUNO $(+5-50)$ & 3,42 & 2173 \\
\hline
\end{tabular}
gempa arah X 100\% dan arah Y 30\%. Begitu pula sebaliknya, pada kasus beban EQY diberikan beban gempa arah Y sebesar $100 \%$ dan arah X sebesar 30\% (Tabel 5).

Tabel 5. Beban Lateral per Tingkat Arah $X$ dan

(f) Simpangan antar lantai

Untuk mengetahui kinerja batas layan dan ultimat, diperlukan data hasil simpangan per lantai dengan menampilkan deformasi akibat EQX (Gambar 12) atau EQY (Gambar 13).

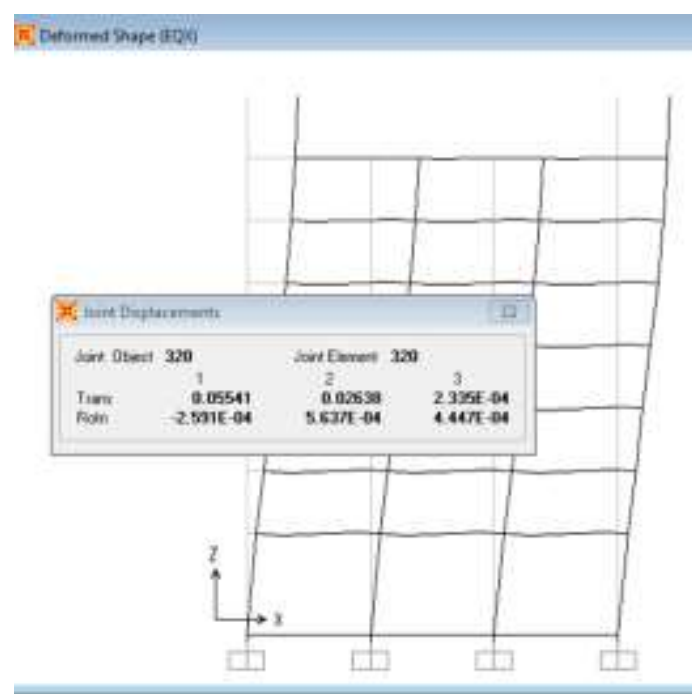

Gambar 12. Deformed Shape (EQX)

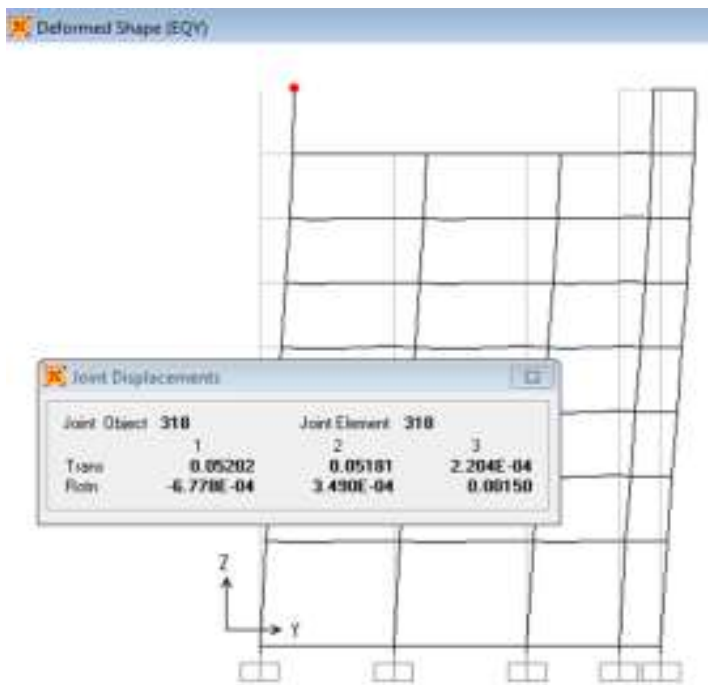

Gambar 13. Deformed Shape (EQY)

Perbedaan defleksi pada pusat massa ditingkat tearatas dan terbawah digunakan untuk menentukan simpangan antar lantai $(\Delta)$. Simpangan antar lantai arah sumbu $\mathrm{X}$ diambil Portal B (Tabel 6) dan arah sumbu Y diambil Portal 2 (Tabel 7).

Sedangkan simpangan antar lantai ijin $(\Delta a)=0,020 h_{s x}$ $=0,020 \times 4050 \mathrm{~mm}=81 \mathrm{~mm}$

Karena $\Delta i<\Delta a===>\mathrm{OK} ! .$. 
Tabel 6. Simpangan Antar Lantai (EQx)

\begin{tabular}{|c|c|c|c|c|c|}
\hline Inglat betai & bx & jiut & $\begin{array}{l}\text { 6et } \\
\text { (mmi) }\end{array}$ & $\begin{array}{c}\Delta t=\frac{\left(\delta e i-\delta e^{\prime}\right) x C d}{l e} \\
\text { (mait) }\end{array}$ & $\begin{array}{c}\Delta a=0,0,02 \text {, hisx } \\
\text { (min) }\end{array}$ \\
\hline Athes & 4050 & 320 & 55.40 & 13.75 & 61 \\
\hline Lahis? & 4000 & 264 & 5290 & 2365 & 81 \\
\hline Latbi 6 & 4050 & 224 & 860 & 34.1 & 81 \\
\hline Lathis & 4050 & 184 & 240 & 41.25 & 81 \\
\hline Lathis & 4050 & 144 & 3490 & 44 & 81 \\
\hline tathi3 & 4050 & 91 & 250 & 45.65 & 81 \\
\hline Lathi2 & 4050 & 47 & 1860 & 45.1 & 81 \\
\hline Lathil & 4050 & 6 & 10.40 & 57.2 & 81 \\
\hline
\end{tabular}

Tabel 7. Simpangan Antar Lantai (EQy)

\begin{tabular}{|c|c|c|c|c|c|}
\hline Tinghat butai & (min) & jist & (mi) & $\begin{array}{c}\Delta i=\frac{\left(\delta e i-b i^{i}\right) \times C d}{i t} \\
(\mathrm{~mm})\end{array}$ & $\begin{array}{c}\Delta a=0,0,02+h s y \\
(\mathrm{~mm})\end{array}$ \\
\hline Alyp & 4050 & 318 & 5200 & 121 & B1 \\
\hline Lata'? & 4050 & 26 & 4980 & 20.9 & 81 \\
\hline Latấ 6 & 4050 & $m$ & 46.00 & 31.9 & 81 \\
\hline Latte 5 & 4050 & 182 & 4020 & 39.05 & 81 \\
\hline Lantie 4 & 4059 & 102 & 33.10 & 41.8 & 81 \\
\hline Latis 3 & 4050 & 106 & 850 & 2.9 & 81 \\
\hline Latte? & 4050 & 49 & 13.20 & 43.45 & 81 \\
\hline Latte 1 & 4050 & 8 & 980 & 53.9 & 81 \\
\hline
\end{tabular}

\section{KESIMPULAN DAN SARAN}

\subsection{Kesimpulan}

Kesimpulan yang bisa diambil, bahwa perhitungan manual sesuai SNI 1726 : 2012, nilai gaya geser dasar $V$ dari analisis statik didapatkan $103.039 \mathrm{~kg}$ untuk arah $\mathrm{x}$ dan $\mathrm{y}$. Sedangkan simpangan antar lantai struktur lebih kecil dari simpangan antar lantai ijin $(\Delta i$ $<\Delta a)$.

\subsection{Saran}

Nilai gaya geser dasar $V$ statik ini bisa dipakai acuan untuk perencanaan struktur gedung rektorat Unhasy Tebuireng Jombang, karena bentuk gedungnya yang beraturan.

\section{DAFTAR PUSTAKA}

[1] Satyarno, Iman, dkk, Belajar SAP 2000 Analisis Gempa (seri 2), Yogyakarta: Zamil Publishing, 2012.

[2] Badan Standarisasi Nasional, SNI 1726: 2012 Tata cara perencanaan ketahanan gempa untuk struktur bangunan gedung dan non gedung, BSN, 2012.

[3] Indarto, Himawan, dkk, Aplikasi SNI Gempa 1726: 2012 for Dummies, hand-out Shortcourse Teknik Sipil UNNES 2013-A Tribute To Bambang Dewasa. 2013.

[4] Standar Nasional Indonesia, SNI 03-1726-2003 Tata Cara Perencanaan Ketahanan Gempa untuk Bangunan Gedung, Bandung, 2003.

[5] http://puskim.pu.go.id/Aplikasi/desain_spektra _indonesia_2011 